\title{
A paixão pela imagem: o eu como cenógrafo das virtualidades do si mesmo
}

\author{
Marina Pinheiro*1
}

É propósito do presente trabalho perscrutar, através das expressões culturais da virtualização do si mesmo, a equivocidade pendular entre o fetichismo comum e as formas de estetização do desejo na atualidade tecnológica. Desde a primeira formação egoica, "projeção de superficie" do olhar materno, ao ego virtualizado nas marcações corporais extremas, ou mesmo avatarizado nos games e redes sociais; torna-se necessário à psicanálise a discussão sobre a dialética entre objetificação e possibilidades de autoração simbólica da existência na contemporaneidade.

Palavras-chave: Fetichismo, virtualidade, imago corporal, cultura

${ }^{*}$ Universidade Federal de Pernambuco - UFPE (Recife, PE, Br). 


\section{ARTIGO}

\section{Introdução}

No universo das humanidades que se debruçam sobre as mutações culturais, a discussão acerca da virtualidade digital tende, cada vez mais, a sair de qualquer compreensão que a antagonize em relação à "realidade", ou, melhor dizendo, à vida off-line dos sujeitos. A irredutibilidade da dimensão virtual a quaisquer tentativas de polarização conceitual ganhou expressiva força a partir do incremento dos smartphones, artefato propulsor de uma convergência de mídias inédita. Num único aparelho, sem fios, compatível com o tamanho do bolso, é possível deslocar-se/transpor-se às determinações de nossa contingência presencial e viajar numa janela infinita de paisagens interativas. Como um verdadeiro álibi ante a possibilidade de experimentação da solidão, do tédio, do "nada a fazer", torna-se possível uma conexão aparentemente escamoteadora do sentimento de nossa inadequação fundamental.

Num exercício de aproximação histórica, ao final do século XIX, época do nascimento das viagens de trem, o livro de bolso emergia como uma "ferramenta para tolerar a inconveniência" da transformação da condição de viajante para a de passageiro. Nessa grande inovação da mobilidade vitoriana, o confinamento ao vagão, o tremor das carruagens nas railways, e, especialmente, o olhar intrusivo de outros passageiros, poderia ser neutralizado pelo mergulho numa novela literária, já que a paisagem tornara-se um cenário de aparente estaticidade panorâmica, e, ao mesmo tempo, fugidia, sempre a desaparecer. Como uma mídia dentro de outra mídia, a leitura se firmava como um hábito viabilizador de um deslocamento outro, que não o do trajeto ferroviário. Assim, se as estradas de ferro destituíram a tradicional experiência do viajante, que de condutor passara a ser conduzido - sentindo-se como um elemento de entrega à destinação final —, a leitura o aproximava da possibilidade de alguma fruição do sujeito na relação espaço-tempo, através das narrativas da mídia impressa da época (Parikka e Suominen, 2006). 
$\mathrm{Na}$ atualidade, a leitura é substituída pelas telas responsivas ao toque, janelas imagéticas, cuja narrativa pode ser aventurada numa participação ainda mais imersiva, vez que o leitor se avatariza no hipertexto, redesenhando sua identidade ontológica por via da transicionalidade virtual. Freud, em "O mal-estar na civilização", comenta a propósito do lugar da tecnologia na cultura: "Essas coisas não apenas soam como um conto de fadas, mas também constituem uma realização efetiva de todos - ou quase todos - os desejos de contos de fadas" (Freud, 1930/1974, p. 111). No texto freudiano, as invenções técnicas, como ampliadoras das capacidades dos órgãos sensoriais e motores, atualizariam, assim, aquilo que seria próprio ao campo da fantasia. Numa releitura da proposição freudiana no campo da experiência mediada por computadores, Diana Corso (2011) comenta:

Frente ao sexo nos sentimos da mesma forma do que em relação aos computadores: neles sempre há muito mais funções e possibilidades que não sabemos explorar. Mesmo aos mais ousados resta a ideia de estar subutilizando sua 'máquina' e hoje não perdoamos a vida que não entregue a todo o gozo que nos devia.

O avatar, termo de origem hindu que significa encarnação, popularizou-se no vocabulário das mídias digitais devido ao recurso de criação, pelos usuários, de figuras à imagem e semelhança de suas preferências estéticas, transcendendo, assim, as limitações de seu corpo biológico. Pela via do simulacro digital, tudo se torna possível, como no campo das artes e da criação lúdica. O corpo avatarizado é um corpo para ser usado, um corpo-extensão do sujeito, imune às fragilidades da normativismo vital. Enfatizo que, diferentemente de uma second life, ${ }^{1}$ os limites do que ocorre na virtualidade e no mundo off-line são bastante porosos, difusos, como é o caso da estudante e programadora que pagou seu curso universitário, prostituindo seu avatar numa plataforma digital multiplayer, ${ }^{2}$ ou ainda, como tem se tornado comum em diversas funerárias, é possível a despedida de um ente falecido sem participar presencialmente do funeral, pois o velório on-line não só passa em tempo real as imagens da sala fúnebre, como também é possível enviar mensagens, flores, fotografias de momentos felizes vividos com o finado. É conhecida também a situação de usuários de redes sociais em que, mesmo após sua morte, a página de seu avatar virtual continua efetivando, colaborativamente, diálogos e postagens,

${ }^{1} \mathrm{O}$ termo second life popularizou-se através de um ambiente virtual, em 3D que simula os mais diversos aspectos da vida social, sendo considerada uma plataforma que converge a função de jogo, simulador, comércio e rede social.

${ }^{2}$ Multiplayer significa jogo que permite milhares de participantes simultâneos no mesmo ambiente virtual. 


\section{ARTIGO}

negando a perda real. O ciberespaço como universo de suspensão das limitações do mundo off-line, negaria a falta estrutural através do primado da plasticidade, do editável e da abreviação discursiva/simbólica.

\section{Virtualidade digital e o ego editável}

Neste registro, a vida do outro, par da cultura, torna-se novela participativa, incitativa à visualização, paisagem de pura potência às encenações desejantes. A lógica do ver e ser visto, em especial nas redes sociais virtuais, recebe sua expressão máxima, predicando o ideal do "ser desejável/invejável", como condição de paradoxal reconhecimento de sua diferença, efeito da crepusculização das referências simbólicas universalmente aceitas. Como sabemos, o questionamento das práticas e dos modelos tradicionais, a incitação à autofundação, à individualização, à reinquirição do próprio desejo, são atributos característicos do sujeito da atualidade, desencantado das supostas garantias e da consistência do sistema de filiação vertical. As subjetividades formadas pelo testemunho da precariedade da Igreja, da família e do Estado, comprazem-se através do sonho da diferença singularizante (da estética corporal, dos modos de vida, do consumo), refúgio costumizável para o movediço cenário neoliberal.

Como videomakers de sua própria autobiografia, a virtualidade digital do "si mesmo", ego editável do sujeito, constitui-se como uma solução de compromisso bastante curiosa, pois através dela um diário imagético-narrativo é produzido e compartilhado com uma audiência de identidade tão avatarizada, editada, quanto o próprio diário. Na perspectiva crítica da atualidade, essas produções típicas de nossa cultura se enquadrariam no campo da impostura e da anomia, pois o nome próprio, aquele que reporta ao não editável da história e da singularidade, produzidas pelo traço do significante, seriam escamoteadas, elididas. O ideal contemporâneo da autofundação identitária encontraria uma forma de atualização na qual o assassinato simbólico, o parricídio, nunca teria ocorrido, posto que o pai, imaginariamente, sempre fora ausente no exercício da autocriação. Nessa perspectiva, da pré-história de nosso nascimento até o fim dos nossos dias, seria enquanto uma espécie de precipitado heterogêneo, uma unidade tensa e dialética formada por uma multiplicidade de identificações, que nos reconhecemos enquanto um "eu", um "si mesmo". Vale a pena apresentar uma citação em que Barthes (1984) descreve seu mal-estar ao ser fotografado, no livro A câmara clara.

Diante da objetiva, sou ao mesmo tempo: aquele que eu me julgo, aquele que eu gostaria que julgassem, aquele que o fotógrafo me julga e aquele de que ele serve para exibir sua arte. Em outras palavras, um ato curioso: não paro de me imitar, e 
é por isso que, cada vez que me faço (que me deixo) fotografar, sou infalivelmente tocado por uma sensação de inautenticidade, às vezes de impostura (como certos pesadelos podem proporcionar). Imaginariamente, a Fotografia (aquela de que tenho a intenção) representa esse momento sutil em que, para dizer a verdade, não sou nem sujeito nem um objeto, mas antes um sujeito que se sente tornar-se objeto: vivo uma microexperiência de morte (...) O que vejo é que me tornei Todo-Imagem, isto é, a Morte em pessoa; os outros — o Outro — desapropriam-me de mim mesmo, fazem de mim, com ferocidade, um objeto, mantêm-me à mercê, à disposição, arrumado em um fichário, preparado para todas as truncagens sutis. (pp. 27-29)

Barthes aborda de modo intenso o horror da captura pelo olhar do Outro. A objetiva, como ele descreve, infringe um crime ao mortificar sobre o peso da paralisia da imagem, sua dimensão pulsátil, dispersa, dividida, agitada, desejante. Colocando-se no lugar daquele que olha a si mesmo, Barthes alude a uma imitação infinita de si, um poço sem fundo (vazio absoluto), como quando colocamos dois espelhos justapostos. A sensação de "inautenticidade" emerge como estranhamento de uma verdade inapreensível nem pelo olhar do fotógrafo, nem pelo próprio Barthes. A cristalização da pose objetifica aquilo que resistiria à imobilidade provocada pela ferocidade do Outro, desapropriador de seus 88 traços desconhecidos e singularizantes. A totalidade da imagem é sentida como uma experiência de morte; é colocar-se em submissão radical a um olhar que o consome, restando nem sombra do desejo de um morto.

Contudo, conforme já dito, no horizonte digital, a suposta totalização produzida pela imagem seria ficcionada não com o horror da objetificação pelo Outro primordial, mas como totalização autofundada, livre de quaisquer heranças, posto que escolhida no vocabulário da vontade e da manipulação do sujeito. Nesse contexto, a alteridade surge apenas no campo do reconhecimento narcísico pelo pequeno outro, ou ainda no assombro de seus usos imprevistos em rede. Se por um lado ela é editável à imago sonhada, ou ainda ao mito individual do "usuário da rede", por outro lado, assim como a palavra dita, o controle sobre suas destinações e usos em muito pode se distanciar da gramática do controle, num universo onde a lei é precária em suas formas de perscrutação.

Num fórum on-line de discussão sobre, conforme postado, "por que a mania adolescente de tirar fotos na frente do espelho?", leem-se as seguintes respostas à questão (http://yhoo.it/1bG5TaY):

- "tipo laboratório de ator, fazendo poses e bocas até encontrar uma para si."

- "Ah... eu também gosto de tirar fotos na frente do espelho. Quando se é jovem, é normal se admirar! Quando as pessoas ficam mais velhas, perdem um pouco esse gosto e preferem fotos com mais sentido." 
- "Vergonha de pedir pra alguém tirar foto, principalmente quando são fotos mais sexy."

- "É para que numa mesma foto já saia a 'frente' e o 'verso'."

Num outro fórum (http://bit.ly/13vCyg5), que discute como produzir fotos de acento mais sensualizado, uma das participantes comenta:

- É muito excitante, em primeiro lugar. Você se sente renovado por suas habilidades eróticas. Você conseguiu lutar contra a sua baixa autoestima, exalando confiança on-line. No entanto, há limites. Nunca dê mais do que inicialmente pretendido.

Ao ler essas respostas, a perspectiva de Bakhtin (2003), filósofo do dialogismo, emerge como uma metáfora bastante própria aos autorretratos digitais, ao ego editável do sujeito. Para o autor: "Nunca estamos sozinhos frente ao espelho, é preciso tornar-se um outro em relação a si mesmo no acontecimento da autocontemplação" (p. 33). Buscando tornar-se um outro em relação a si mesmo (eu-para-os-outros), num semblante de autoria em relação à vida-obra-viva e sobredeterminada, tentar-se-ia espreitar a refração projetiva do que nos escapa e, por isso mesmo, é dotado do mais intenso valor. A estilística existencial seria fortemente marcada pelo movimento de inatingível captura do que nos ultrapassa, nosso transgrediente de visão, figuração do estranho-familiar que parece ser suspendida na paixão pela imagem avatarizada de si.

No assim chamado sexo virtual, os atores exibem - no enquadre parcial e possível da câmera digital (é impossível ver o corpo inteiro nela) — a fotografia responsiva e editada pela miragem do desejo e do orgasmo anunciado, em resposta ao apelo de satisfação advindo do outro. Nada muito diferente do sexo off-line, marcado pela perversão fundamental da condição humana pela linguagem, aquela que nos arrancou da ordem da Natureza. Contudo, o que se torna curioso através dos incrementos tecnológicos é o sexo virtual com avatares de programação, em plataformas de dating $\operatorname{sim}^{3}$ e hentai games. ${ }^{4}$ Nesses ambientes, o epic win $^{5}$ de tais jogos de conquista se caracteriza pelo ato sexual com um avatar programado que simula um orgasmo, numa prática sexual que

${ }^{3}$ Tipo de video game de simulação que contém elementos românticos que visam promover encontros e relações do gênero.

${ }^{4}$ Jogo erótico de computador, de origem japonesa, com uso de imagens de sexo explícito.

${ }^{5}$ Em sua tradução literal significa vitória épica, na linguagem dos jogos refere-se à conquista da pontuação máxima de um jogo ou sua etapa. 
poderíamos considerar como lúdica, que dispensa qualquer alteridade subjetivante do objeto. Nesse caso, o ilusionismo é efeito da pura projeção fantasmática sobre a rigidez objetiva do frame programado para o avatar. Nesse contexto, é interessante reler uma passagem da entrevista de uma streaper a James Strachey, que na época recebera o emblema "feita para ser um fetiche". Seu nome era Olympia.

Tento manter-me receptiva ao que eles querem ver e manter-me tão arquetípica quanto possível de modo que a plateia veja o que quer ver (...). Sentia-me completamente destacada de meu corpo, sentia-me como uma entidade totalmente separada dele. Ainda vejo meu corpo como uma ferramenta, como algo a ser usado. (apud Safatle, 2010, p. 55)

Vladmir Safatle (2010) propõe a compreensão sobre o fetiche como uma forma específica de encantamento dos sujeitos modernos, engendrada solidariamente em contextos de desencantamento na palavra. "Em vez de um não querer saber, o fetiche seria um saber impotente diante da crença" (p. 107). Se pensarmos nas práticas sexuais com avatares de computação, torna-se evidente que a tecnologia em si, diferentemente das versões apocalípticas da contemporaneidade, não nos conduz à objetificação do outro. Nenhuma ferramenta é, per se, portadora de um propósito, só as ações humanas o são. Sendo assim, parece-me que o virtual aproxima-se muito mais de uma transicionalidade lúdica, por vezes, criativa, que um dispositivo de apagamento da alteridade. Nas palavras de Joyce McDougall (1983): “A maioria das pessoas ignora seu núcleo perverso, tanto quanto desconhece suas potencialidades criativas. Aquele está sepultado sob os traços de caráter, está confinada nos sonhos: os dois reencontram-se nesse outro palco constituído pelo inconsciente" (p. 68). Poderíamos hoje, então, adicionar um segundo palco: o dos ambientes de extensão virtualizada da existência.

\section{Questões sobre o corpo e virtualidade}

A partir do que foi abordado nas seções anteriores, faz-se necessária uma incursão, mesmo que sucinta, sobre o lugar do corpo nos impasses fundamentais da constituição do sujeito, como forma de nos aproximarmos da dialética entre objetificação e autoração simbólica da existência, assim como do movimento pendular entre fetichismo e as formas de estetização do desejo na atualidade.

Para a psicanálise crítica da cultura, tornou-se lugar comum a concepção de que a cena psicopatológica atual seria prenhe de formações sintomáticas nas quais o destino da angústia sofreria uma espécie de "curto-circuito". Esse curto representaria, então, um sobreinvestimento na corporeidade apreendida pelo sujeito 


\section{ARTIGO}

como causa e, ao mesmo tempo, terapêutica de seu transtorno páthico. O corpo seria experimentado, assim, como uma abreviação que designaria o mal e o seu próprio antídoto; o desconforto e o alívio; o transtorno e a sua cura; num princípio homeopático às avessas, posto que não seria em pequenas medidas do próprio princípio corporal que a mudança ocorreria. Pelo contrário, o excesso, o extreme (cirúrgico, psicofarmacológico, psicotrópico ou sensorial) impõe-se como única via de uma transformação reparadora do mal-estar.

Nessa metáfora, o curto seria, assim, provocado pela supressão, precarização, ou ainda, desinvestimento da palavra como dispositivo fundamental à assunção, pelo sujeito, da condição nietzschiana de poeta forte de sua história. O dispositivo psicanalítico encontraria, assim, nesses modos de subjetivação "corpo-centrados", um forte desafio à sua prática sustentada na palavra como possibilidade do sujeito em redescrever-se singularmente, produzindo, assim, novos destinos ao que não cessa de fazer-se repetir num mal-estar aprisionante. As adicções, compulsões diversas, bulimias, anorexias, síndromes do pânico, as depressões, enfim todas essas expressões sintomáticas em alta recorrência clínica estariam relacionadas, em alguma medida, a um desinvestimento da possibilidade de provocar, através da simbolização, novas causalidades, ou de estabelecer ficções menos objetificantes de si.

Num olhar sócio-histórico, o desinvestimento na esfera do bem comum; o individualismo; a cultura do espetáculo; a fragilização dos laços sociais; a corpolatria midiática; a tecnologização da medicina; enfim um verdadeiro caldeirão apocalíptico da falência de tradicionais agências doadoras de identidade é apontado como uma das matrizes explicativas dos modos de subjetivação "corpocentrados" e narcisicamente organizados. São incontáveis os artigos que trazem essa espécie de descrição como modo de justificar, culturalmente, por quais vias seriam produzidos esses modos de ser-no-mundo, mundo esse que parece ser "sem coração" (Lasch, 1991).

O homem tradicional cede lugar ao homem moderno inserido no universo da técnica, massificado no transcorrer do desenvolvimento industrial. Isolado, desenraizado, este homem caminha apressadamente no fluxo da multidão. A imagem do homem-autômato das grandes cidades é a imagem do homem que perdeu os laços com a elaboração e a transmissão da experiência. A imagem do mundo moderno é a de um mundo que já não oferece condições para a elaboração e a transmissão da experiência. (Schimidt apud Ferraz, 2003, p. 17)

A paisagem contemporânea apresentaria mutações que estabeleceriam uma economia psíquica, muito diferente daquelas que Freud descreveu a partir de sua histérica. Ali onde se escutavam conflitos e sintomas marcados pela interdição aos desejos, hoje se inscreveria um mal-estar que se daria pelo fracasso ao atendimento da norma do exibicionismo e do imperativo de um mais gozar; 
ali onde se reconhecia a falta e a insatisfação como matriz da neurose, hoje nos deparamos com o excesso dos modos de satisfação pulsional ao mal-estar objetificado no corpo; ali onde o limite se oferecia como campo para exploração de novos sentidos da existência, hoje o enquadraríamos como um "defeito" a ser reparado através das mais diversas tecnologias acessíveis ao homem, um produto a ser consumido na voracidade dos apetites de seu consumidor.

Nesse sentido, é como se o corpo fosse submetido a uma engrenagem cultural de um Outro que o objetificaria, apagando nessa operação, qualquer dissonância ou iato entre a materialidade precária da corporeidade e a fantasmática das imagens perfeitas, desprovidas de furos. No contexto do ego editável, é curioso pensar na compreensão da estudante, mencionada anteriormente, sobre a atuação sexual de seu avatar como prostituta numa plataforma multiplayer:

Eu sentava em frente ao computador com os livros na mão e brincava de copiar e colar meu arsenal de textos eróticos e apertar os botões com sons específicos. Quando me sentia inspirada, bancava a terapeuta, ouvindo e aconselhando os clientes, sempre com palavras doces e encorajadoras. O sexo virtual no Second Life acontece a maior parte do tempo verbalmente, a parte visual é garantida pelas poses programadas, embutidas em uma cama ou outra mobília com um controle de movimentos. É tudo automático, e o prazer de cada um advém de sua própria criatividade e imaginação. ${ }^{6}$ (Revista Continente, 2013)

De forma semelhante ao fragmento de fala da streaper referida anteriormente, o corpo virtualizado/avatarizado apresenta-se como corpo para ser usado, uma extensão alteritária de si mesma, que seria, simultaneamente, dissociada e ofertada como paisagem para as projeções fantasmáticas do outro, para a encenação instantânea da fantasia, num role-playing ${ }^{7}$ digital. Contudo, permanece como questão sobre quais seriam as nuances diferenciais entre Olympia, que emprestava sua própria pele como superfície projetiva para a voyeurização do outro, e a estudante programadora, que por meio de um simulacro digital encarnava por via de bits e bytes, a prostituta para sexo entre avatares. Se encontramos, numa acepção wittgensteiniana, certa semelhança de família no campo do discurso e da narrativa dessas duas mulheres, por outro lado, talvez seja no Significante, aquele que produz a singularidade diferencial por via de um corte nas relações junto ao outro social, par da cultura, que a corporeidade inaugura novas metáforas, destinações ampliadoras do circuito desejante. Pouco sabemos

${ }^{6}$ Recuperado em 24/2/2015, de: <https://sexodoispontozero.wordpress.com/2014/09/15/ fetiches-online-x-empreendedorismo/\#more-149>.

${ }^{7}$ Role-playing game é também conhecido como RPG; é um tipo de jogo no qual os participantes atuam através de personagens produzindo, colaborativamente, narrativas e enredos. 


\section{ARTIGO}

de Olympia, mas no caso da programadora, a aparente instrumentalidade do avatar potencializou reescritas de si, furos de circulação entre identidades possíveis. Na passagem do gozo imaginário, narcísico, à abertura metonímica do desejo, desenha-se uma gangorra contemporânea que não admite polarização simplificadora, mas a assunção do enigma sobre o estatuto da corporeidade e das formas de autoração da existência.

A virtualidade do contexto aludido faz-nos indagar sobre qual o lugar dessa corporeidade avatarizada no discurso psicanalítico, como esse corpo se prestaria à redescrição simbólica ou à objetificação paralisante da imagem, posto que, antes de qualquer incremento tecnológico, o corpo humano se constitui na e pela virtualidade fundamental da linguagem.

Numa acepção básica do tema, conforme sabido, afirma-se que o corpo em psicanálise não é o corpo natural, biológico, ou ainda o corpo descrito pela anatomia dotado de uma organização independente da linguagem. $\mathrm{O}$ corpo ao qual a psicanálise se endereça é o corpo apossado/produzido pelo simbólico, irredutível ao corpo que encontramos nas ciências da saúde, como na medicina. Essa irredutibilidade assume como ponto de partida a linguagem, condição de qualquer proposição acerca da subjetividade. Se nos fosse possível falar de um "começo absoluto", este se colocaria no lugar do significante, campo ao qual somos lançados em nosso devir. Assim, no antiessencialismo provocado pela episteme psicanalítica, seria por via da matriz simbólica constitutiva que a condição humana perfaz-se enquanto horizonte radicalmente distinto ao dos vocabulários deterministas e unidirecionais dos instintos, das necessidades, da natureza.

Colocar a linguagem, ou ainda o significante, como estatuto primordial de qualquer asserção sobre a subjetividade em psicanálise não significa, contudo, um reducionismo linguístico. O simbólico, ao mesmo tempo que produz a "desnaturalização" do corpo e da existência, sua submissão à ordem significante, instaura também o corpo pulsional que é da ordem do não representável, num além da linguagem que só pode ser pensado através dela mesma. $\mathrm{O}$ corpo pulsional é, portanto, efeito da incidência da letra sobre o corpo, e não há anterioridade a essa incidência.

Isto significa dizer que a linguagem, em sua intervenção subjetivante, implica a "presença de uma ausência", uma falta constante própria à estrutura da língua produtora de efeito-sujeito-dividido. A falta seria a marca antimetafísica da psicanálise, donde, por via da própria concepção de linguagem, posiciona uma inextinguível incompletude no ser. "A perda do objeto absoluto é a perda de algo que nunca foi tido, já que a psicanálise se situa desde o começo no lugar da linguagem" (Garcia-Roza,1990, p. 67).

À luz dessa construção, apreende-se como o corpo encarna-se/vive/subsiste, paradoxalmente, como imago corporal, "projeção de superfície" (no vocabulário 
freudiano), produzida através de um elemento exterior, qual seja: o signo do Outro. O traço unário, apesar de aludir ao um, não deve ser confundido com unidade. Sua função estaria no campo da unicidade singularizante do sujeito, uma vez que, forjado num jogo identificatório da semelhança/especular, precipita-se como marca indelével da diferença, quebra da alienante ilusão do mesmo. De acordo com de Nasio (2009):

Se o corpo imaginário é o corpo quando produz sentido, corpo simbólico é o conjunto de nomes e metáforas que simbolizam diversos aspectos de nosso físico e, sobretudo, que têm o poder de produzir efeitos em nossa vida. Em outros termos, se o corpo imaginário é uma imagem que engendra sentido, o corpo simbólico é um significante que engendra efeitos concretos em nossa realidade. (p. 115)

Se utilizarmos essa proposição como uma lógica que performatiza também a questão da singularidade como processo de autoração da existência, do tornar-se poeta forte de sua história, leríamos que a singularidade corpocentrada trabalharia em função da falicização da diferença, de inflacionamento egoico, repetindo uma objetificação imaginária. A singularidade, simbolicamente sustentada, prestar-se-ia à possibilidade de o sujeito contar-se como menos um. Desinvestido das promessas de aprisionante completude implicar-se-ia na produção de destinos mais criativos à angústia de sua finitude/limite/vulnerabilidade. Ocupando-se de sua vida como obra sempre inacabada, veria na possibilidade de estetização da existência por sua singularidade o legado mais satisfatório a ser recoberto sob seu nome. Retomando a metáfora da gangorra sobre as disposições da corporeidade contemporânea, virtualizada através do simbólico, poderíamos sintetizar os seguintes eixos interpretativos:

- Singularidade imaginarizada: a diferença seria experienciada como atributo-fetiche de um eu que busca completar-se, através da incorporação voraz, de uma onipotência mágica encarnada no real do corpo. Nessa operação, a singularidade instaurar-se-ia como uma verdade/sentido mítico do ser, que, apesar de inapreensível objetivamente, desfilaria aos olhos do sujeito como o sonho de uma totalização de si. Essa totalização seria ficcionada não com o horror da objetificação pelo Outro primordial, mas como totalização autofundada, posto que escolhida no vocabulário da vontade/necessidade do sujeito.

- Singularidade simbólica: produzida pela identificação do sujeito à falta, a singularidade (ordenada pelo significante) ocorreria como aquela que advém do desinvestimento de emblemas fálicos. Nessa construção, a singularidade seria experienciada como gatilho de satisfações diversas, plasticamente lançada ao fluxo metonímico do desejo. Nessa formação, encontraríamos o sujeito que ressignifica polissemicamente sua história, que imprime sua marca subversiva 


\section{ARTIGO}

na realidade simbólica a que participa, como mais um representante. Num permanente movimento de ruptura à inércia do sentido, nessa organização o sujeito descobre novas formas de erotismo, de investimento na vida, no outro.

Nesse sentido, a virtualização da imago corporal parece oscilar entre as polaridades supracitadas, numa diversidade fenomenológica-cultural de impossível trabalho de generalização. Dos projetos corporais antinormativos, tais como as modificações extremas com implantes subcutâneos de silicone, bipartição de língua, cobertura de toda extensão de pele por tatuagens; manipulações estéticas do corpo com vistas ao apagamento de heranças, ou ainda, as tecnologias digitais de modificação e avatarização da imagem, seria apenas nas formas de endereçamento do discurso, inscrito no corpo, ao Outro que qualquer dizer sobre a subjetividade contemporânea é viabilizada. Na gramática do referido ego editável da vida on-line, o aparente acabamento fetichista da autoimagem pode perfazer-se enquanto dobra ou potencialidade de travessia/percurso do processo de redescrição das narrativas de si, estetizantes do deslizamento metonímico sobre os objetos do desejo.

Num momento histórico de fortes injunções de massificação midiática de novos dispositivos de controle imagético e social (panópticos digitais), visibilidade e virtualidade parecem formar um par dialógico de um jogo especular interminável. Numa linguagem bakhtiniana, o "excedente de visão", o campo cego da imagem insondável do si mesmo, é objeto do mais intenso investimento para a subjetividade atual.

\section{Referências}

Bakhtin, M. (2003). Estética da criação verbal. São Paulo: Martins Fontes.

Barthes, R. (1984). A câmara clara. Rio de Janeiro: Nova Fronteira.

Corso, D. (2011). Amadores do sexo - Sobre Bruna Surfistinha e a prostituição. Recuperado em 1 fev. $2016 \mathrm{de}<\mathrm{http}: / / w w w . m a r i o e d i a n a c o r s o . c o m / a m a d o r e s-d o-s e x o>$.

Ferraz, F.C. (2003, março). A loucura suprimida: normopatia, sociedade e sociedades psicanalíticas. Pulsional Revista de Psicanálise, São Paulo, (167), 15-23.

Freud, S. (1974). O mal-estar na civilização. In Edição Standard Brasileira das Obras Psicológicas Completas de Sigmund Freud (vol. XXI). Rio de Janeiro: Imago. (Trabalho original publicado em 1930).

Garcia-Roza, L.A. (1990). O mal radical em Freud. Rio de Janeiro: Jorge Zahar.

Lasch, C. (1991). Refúgio num mundo sem coração. Rio de Janeiro: Paz e Terra.

Lebrun, J-P. (2003). Prefácio. In C. Melman, O homem sem gravidade: gozar a qualquer preço. Rio de Janeiro: Companhia de Freud. 
McDougall, J. (1983). Em defesa de uma certa anormalidade: teoria e clínica psicanalitica. Porto Alegre: Artes Médicas.

Nasio, J.-D. (2009). Meu corpo e suas imagens. Rio de Janeiro: Jorge Zahar.

Parikka, J. \& Suominen, J. (2006, dezembro). Victorian Snakes? Towards a Cultural History of Mobile Games and the Experience of Movement. Game Studies, 6(1). Recuperado em 14 dez. 2013 de < http://bit.ly/1j7bi1q>.

Roudinesco, E. (2009). Our Dark Side: a History of Perversion. Cambridge: Polity Press.

Safatle, V. (2010). Fetichismo: colonizar o outro. Rio de Janeiro: Civilização Brasileira. (Para ler Freud)

\section{Resumos}

(The passion for images: The ego as scenographer of the virtualities of the self)

The aim of this paper is to investigate, through cultural expressions of selfvirtualization, the pendulum equivocity between common fetishism and the forms of aestheticizing desire in the current technological scenario. Since first ego formation, "surface projection" of the maternal gaze, as far as the virtualized ego in extreme body modifications, or even as an avatar in games and social networks; discussion concerning the dialectic between objectification and symbolic authoring possibilities of existing in present culture is necessary to psychoanalysis.

Key words: Fetishism, virtuality, body image, culture

(La passion pour l'image: Le moi comme décor des vertus du soi-même)

Cette étude vise à scruter, à travers les expressions culturelles de la virtualisation du soi-même, l'équivocité pendulaire entre le fétichisme commun et les formes d'esthétisation du désir dans l'actualité technologique. De la première formation égoïque, "projection superficielle»du regard maternel, à l'ego virtualisé dans les marquages corporels extrêmes, ou même avatarisé dans les jeux et les réseaux sociaux; la discussion sur la dialectique entre l'objectivation et les possibilités de création symbolique de l'existence dans la contemporanéité devient nécessaire à la psychanalyse.

Mots clés: Fétichisme, virtualité, imago corporelle, culture

(La pasión por la imagen: el yo como un diseñador de escenarios de las virtualidades del sí mismo)

El propósito de este trabajo es observar, a través de las expresiones culturales de la virtualización del sí mismo, la ambigüedad pendular entre las formas comunes de fetichismo y estetización del deseo en una actualidad tan tecnológica como la 


\section{ARTIGO}

de hoy en día. Desde la primera formación del ego, "proyección de superficie" de la mirada materna, hasta el ego virtualizado en las marcas corporales extremas o incluso avatarizado en los juegos y las redes sociales; es necesario psicoanalizar, la discusión sobre la dialéctica entre la objetificación y las posibilidades de creación simbólica de la existencia hoy en día.

Palabras clave: Fetichismo, virtualidad, imago corporal, la cultura

(Die Leidenschaft für das Bild: das Ich als Bühnenbildausstatter der Virtualitäten des Selbst)

Auf der Basis kultureller Ausdrucksformen der Virtualisierung des Selbst untersucht dieser Artikel die pendelartige Äquivozität zwischen dem allgemeinen Fetischismus und den Formen der Ästhetisierung der Begierde in unserer zeitgenössischen technologischen Gesellschaft. Seit der ersten Ich-Bildung, „,Oberflächenprojektion” des mütterlichen Blicks, bis hin zum virtualisierten Ego der extremen Körpermarkierungen, oder seiner Avatarisierung in Computerspielen und sozialen Netzwerken, tut die Psychoanalyse Not, sowie die Diskussion über die Dialektik zwischen Vergegenständlichung und den Möglichkeiten der symbolischen Darstellung der Existenz in unserer zeitgenössischen Kultur.

Stichwörter: Fetischismus, Virtualität, Imago des Körpers, Kultur

(对图像的迷恋：我作为我自己的虚拟场景)

本论文的目的是, 研究自我虚拟化的条件下网络文化表达, 研究网络技术 下，拜物主义和个人欲望的美学化。当一个人的自我形成后，从母体目光的“ “ 表面投放” 开始, 到纹身并且把纹身拍照放到网路上, 到游戏和社交网站自我 投入和重塑, 对这些过程做心理分析变得重要, 促使人们讨论当代网络文化 中，自我的虚拟化和自我的重塑。

关键词: 拜物主义, 虚拟化, 身体图像, 文化。

Citação/Citation: Pinheiro, M. (2016, março). A paixão pela imagem: o eu como cenógrafo das virtualidades do si mesmo. Revista Latinoamericana de Psicopatologia Fundamental, 19(1), 84-98.

Editores do artigo/Editors: Prof. Dr. Manoel T. Berlinck e Profa. Dra. Sonia Leite 
Recebido/Received: 13.3.2015/ 3.13.2015 Aceito/Accepted: 16.3.2015 / 3.16.2015

Copyright: (C) 2009 Associação Universitária de Pesquisa em Psicopatologia Fundamental/ University Association for Research in Fundamental Psychopathology. Este é um artigo de livre acesso, que permite uso irrestrito, distribuição e reprodução em qualquer meio, desde que o autor e a fonte sejam citados / This is an open-access article, which permits unrestricted use, distribution, and reproduction in any medium, provided the original authors and sources are credited.

Financiamento/Funding: A autora declara não ter sido financiada ou apoiada / The author has no support or funding to report.

Conflito de interesses/Conflict of interest: A autora declara que não há conflito de interesses / The author has no conflict of interest to declare.

\section{Marina Pinheiro}

Professor Adjunto da Universidade Federal de Pernambuco - UFPE (Recife, E, Br); Doutora em Psicologia Cognitiva pela mesma Universidade; Mestre em Psicologia Clínica pela Universidade Católica de Pernambuco - UNICAP (Recife, PE, Br).

Rua Manoel de Carvalho, 226/302 - Aflitos

52050-370 Recife, PE, Br

e-mail: marinaassis.pinheiro@gmail.com

\section{(cc) BY-NC}

This is an open-access article, which permits unrestricted use, distribution, and reproduction in any medium for non-commercial purposes provided the original authors and sources are credited. 